\title{
La frontera eficiente y los límites de inversión para las AFP: una nueva mirada*
}

\section{The Efficient Frontier and the Limits on Investment for Pension Plan Administrators (AFP): A New Perspective}

\author{
Diana Ortiz ${ }^{1}$ \\ Miguel Chirinos ${ }^{2}$ \\ Yvonka Hurtado ${ }^{3}$
}

Recibido: June $1^{\text {st }}, 2010$

Aceptado: July 7, 2010

\section{Resumen}

En este documento se hace una reestimación de la frontera eficiente para las administradoras de fondos de pensiones. El objetivo es doble: de un lado es medir el efecto que tuvieron los límites de inversión impuestos por los reguladores. A diferencia de estudios anteriores, aquí las posiciones cortas no son limitadas; este supuesto se basa en la completitud de mercados financieros: cuando los mercados son completos cualquier instrumento financiero puede ser replicado. El otro objetivo es medir el desempeño de los fondos de pensiones. En trabajos anteriores el desempeño se media como la diferencia entre rentabilidad en la frontera y la obtenida para un nivel de riesgo dado; aquí se mide como la relación rentabilidad riesgo óptima y la obtenida. La conclusión principal es que la regulación validó la toma de elevados niveles de riesgo por parte de las administradoras.

Palabras claves: Desempeño, AFP, CAPM, frontera eficiente, regulación.

\begin{abstract}
This article provides a re-estimation of the pension plan funds administrators' efficient frontier. The goal here is two-fold: on the one hand it measures the effect of investment limits imposed by regulators. Unlike previous studies, here the short positions are not limited; this assumption is based upon the completeness of the financial markets: when the markets are completed, any financial instrument may be replicated. On the other hand, this article measures the performance of the pension plan funds. In earlier works, the performance was measured as the difference between the profitability in the frontier and the one obtained at the level of a given risk; here the return is measured as the relationship of optimal risk profitability and the one obtained. The main conclusion drawn is that regulation supports the high level of risks taken by the administrators.

Keywords: Performance, AFP, CAPM, efficient frontier, regulation.

* Los puntos de vista expresados corresponden estrictamente a los autores y no comprometen a las instituciones a las cuales están afiliados.

1. Banco Mundial

2. Universidad Nacional Mayor de San Marcos

3. Comisión Nacional Supervisora de Empresas y Valores (Conasev)
\end{abstract}




\section{INTRODUCCIÓN}

Con información del trabajo de Pereda, se revisa las conclusiones de las investigaciones de Pereda (2007) y de Rivas-Llosa y Camargo (2002), en las que se mide el impacto de las regulaciones y límites de inversión sobre los fondos de pensiones. En estas investigaciones se concluye que los límites impuestos tuvieron impacto negativos sobre la rentabilidad de los fondos administrados por las AFP. En el presente documento se hace una reestimación de la frontera eficiente de inversión para las Administradoras de Fondos de Pensiones (AFP) en el período 1995-2004. El objetivo que se persigue es doble: por un lado se evalúa el impacto que produjo en la frontera eficiente los límites impuestos por los reguladores y, por el otro, se evalúa el desempeño mostrado por las AFP en esta nueva frontera. En ambos objetivos las metodologías para evaluarlos son distintas, por lo que las conclusiones son cuantitativa y cualitativamente diferentes.

Desde la perspectiva planteada en este nuevo documento, las regulaciones no necesariamente deben tener un impacto negativo sobre la rentabilidad cuando se fijan adecuadamente. Por el contrario, éstas deberían llevar a mejorar los criterios de inversión y a limitar los niveles de riesgo asumidos. Otro aspecto importante es la evaluación del desempeño de las administradoras; la pérdida generada se mide como la diferencia entre la rentabilidad predicha por la frontera eficiente, para un nivel de riesgo dado, y el nivel de rentabilidad que la administradora obtiene para el mismo nivel de riesgo. Alternativamente, se mide como la disminución de riesgo que podría obtenerse si las decisiones de inversión fueran eficientes. La posición asumida aquí difiere en dos aspectos: (a) el primero es el impacto de los límites legales en la estimación de la frontera eficiente; y, (b) el segundo es la forma cómo se mide el desempeño de las administradoras.

Con la información elaborada por Pereda se considera la frontera de posibilidades de inversión para las AFP. Para tal efecto, en una primera etapa se estima la frontera sin restricciones y en la segunda se introducen las restricciones impuestas por los reguladores, como consecuencia se obtiene la frontera eficiente «restringida». La frontera eficiente no limita las posiciones cortas, posibilidad que estuvo descartada en los trabajos de Pereda y de Rivas-Llosa y Camargo. Los mercados financieros completos permiten replicar cualquier posición y, desde esta perspectiva, las posiciones cortas podrían ser obtenidas.

Otro aspecto que difiere significativamente del trabajo de Pereda es la medición del desempeño de las administradoras. Tal como se mencionó líneas arriba, una de las formas de medir el desempeño de las administradoras es determinar la diferencia entre la rentabilidad obtenida y la rentabilidad óptima para un nivel de riesgo dado. Aquí se realiza un cambio cualitativo al medir el desempeño como un ratio entre rendimiento y riesgo; esto es, se utiliza el Índice de Sharpe para medir el desempeño. Ello implica un cambio cualitativo, pues introduce el riesgo en la medición del desempeño de las administradoras.

El presente artículo se divide en cinco secciones. La primera es la introducción. La segunda sección incluye la reestimación de la frontera eficiente tomando en cuenta los aspectos mencionados previamente. En la tercera parte se evalúa el impacto de las regulaciones y límites impuestos por las autoridades. La cuarta sección presenta una comparación con los estudios anteriores. Por último, el quinto apartado presenta las conclusiones a las que se ha llegado.

\section{ESTIMACIÓN DE LA FRONTERA EFICIENTE}

En este documento, la estimación de la frontera eficiente de inversión para las Administradoras de Fondos de Pensiones (AFP) presenta un cambio significativo con respecto de las estimadas previamente: la frontera eficiente aquí estimada no impone restricciones sobre posiciones cortas. Esta «licencia» está basada en el principio de que en los mercados completos cualquier activo puede ser obtenido mediante una combinación de otros activos. 
Cuando los mercados financieros son completos es posible replicar un activo financiero a través de una estrategia que reproduzca el mismo resultado del activo básico; los activos son redundantes en el sentido de que su precio y su resultado se pueden obtener por una combinación (estrategia) de los otros activos (que replican su desempeño). Este fue el principio que siguieron Black y Scholes (1973) y les permitió reproducir el resultado de una opción. El valor de la cartera que reproduce el resultado de la opción debe ser igual al valor de la opción; si así no fuera, se presentarían oportunidades de arbitraje. La estrategia de reproducir una opción a través de acciones y deuda fue lo que permitió hallar el valor de la opción. El marco teórico para la valuación de opciones de F. Black y M. Scholes fue desarrollado años después por Harrison y Kreps (1979) y Harrison y Pliska $(1981,1983)$.

\section{Carteras eficientes sin tasa libre de riesgo en la literatura}

En el análisis teórico, algunos autores han tratado de evaluar el impacto de las restricciones en el plano rendimiento-varianza (desviación estándar). Fama (1971) desarrolló un modelo donde trataba de medir el impacto que ejercía la eliminación del supuesto de la existencia de la tasa libre de riesgo; es decir, los agentes económicos no podían prestar ni endeudarse a la tasa libre de riesgo. Black (1972) desarrolla un modelo de activos de capital donde no existe la posibilidad de invertir en el activo libre de riesgo; a continuación analiza el caso donde no se puede obtener deuda a la tasa libre de riesgo.

En este modelo se introduce la cartera cero beta, que es la que sirve de base para medir el desempeño de una cartera de inversión en una economía sin tasa libre de riesgo. Ross (1977) desarrolla un modelo donde se introducen las restricciones a las posiciones cortas en los activos riesgosos; luego, esta restricción es extendida al activo libre de riesgo. Las conclusiones a las que llega son similares a las de Black: una cartera no correlacionada con la cartera de mercado debe obtener un rendimiento similar a la cartera beta cero. Ross agrega que ambas carteras deben ser eficientes.

\section{Riesgo y rendimiento en situación de equilibrio}

Fama trata de evaluar el impacto de la ausencia de la tasa libre de riesgo en el rendimiento de una cartera de inversión bajo el marco de un modelo de equilibrio general. En este contexto se introduce el consumo y la inversión en un modelo de dos períodos. No obstante ser un modelo que sólo tiene dos períodos, el consumo se toma como dado por lo que no entra en la función de maximización, mantiene los supuestos sobre las preferencias de los agentes; esto es, las preferencias deben ser homogéneas y cuadráticas. Bajo tales restricciones, el modelo de equilibrio general se reduce al clásico Capital Asset Pricing Model (CAPM) de un único período. En este modelo, el primer período es el actual y sólo se debe maximizar respecto del segundo período.

La única restricción impuesta en el modelo de Fama es la referida a la existencia de la tasa libre de riesgo; no se impone ninguna condición respecto de las posiciones cortas. Se maximiza la rentabilidad sujeta a un nivel predeterminado de riesgo, el valor de las participaciones de los activos en la cartera debe sumar la unidad, no se le impone que sean positivos; la restricción de participaciones no negativas Fama la resuelve de otro modo. Los precios de los activos deben ser determinados bajo condiciones de equilibrio general. Cuando se obtiene el equilibrio general, la relación entre rendimiento y riesgo de los activos debe ser tal que la contribución de cada activo a la cartera llevará a que su relación marginal rentabilidad-riesgo sea la misma para todos. Esta condición es la que determina el precio de cada uno de los activos; pero, lo más importante es que la cartera de mercado será la óptima entre todas las eficientes.

La frontera eficiente está formada por todas aquellas carteras cuya varianza es la mínima dada una rentabilidad deseada. Sólo las carteras que se encuentran encima del punto de mínima varianza son eficientes; es decir, para cada nivel de varianza se escoge la cartera de mayor rentabilidad, esto lleva a que un tramo de la frontera eficiente sea desechado. Dentro del conjunto de carteras eficientes, una única cartera tiene la mayor 
relación rendimiento riesgo ${ }^{1}$; a ésta se le denomina cartera tangente.

Fama afirma, sin demostrar, que la cartera tangente es la cartera de mercado; es decir, la cartera que contiene a todos los activos. Esta afirmación debe cumplirse por la condición que se impuso a los precios de los activos; en equilibrio todos deben tener una contribución rendimiento-riesgo equivalente, lo que lleva a que todos sean incluidos. De esta manera se eliminan las posibilidades de posiciones cortas.

Una de las contribuciones más importantes del artículo de Fama es la aparición de un nuevo intermediario financiero: Portfolio Sharing Company. Este agente financiero juega un rol fundamental en el modelo; el Portfolio Sharing es el que permite que los agentes puedan obtener la cartera que desean. Es decir, si un agente no puede tomar posición en algún activo, el Portfolio Sharing tomará posición en este activo y podrá vender parte a los agentes que se vieron limitados antes de la existencia del intermediario. Así, si un agente deseara tener una posición corta, el Portfolio Sharing construiría una cartera con posiciones cortas; luego, vendería participaciones a los agentes de forma tal que estos puedan construir su cartera de inversión con las cantidades de posiciones cortas que les permitirá que su cartera sea óptima. Bajo las condiciones que se construyó el modelo existe una única cartera óptima: la cartera tangente. Los agentes económicos adquirirían participaciones de esta cartera en proporción al riesgo que deseen mantener; el nivel de riesgo es único y corresponde al riesgo de mercado. Las carteras óptimas deberán fijarse sobre una recta que pasa por la cartera tangente y tiene pendiente igual a la relación entre rentabilidad y riesgo óptima ${ }^{2}$; esta recta sería equivalente a la frontera eficiente cuando existe tasa libre de riesgo. Si las carteras son eficientes, los agentes deberían formar sus carteras de inversión como una proporción

1 En un sentido estricto, ésta debe ser la cartera que tiene el mayor Índice de Sharpe.

2 Debe recordarse que para obtener una recta se requiere conocer la pendiente y un punto por donde pase o, alternativamente, conocer dos puntos por donde pase la recta. de la cartera del Portfolio Sharing, lo que implica que el riesgo y la rentabilidad son determinados por:

$$
\begin{aligned}
& E_{k}(R)=x_{k} R_{p} \\
& \sigma_{k}(R)=x_{k} \sigma\left(R_{p}\right)
\end{aligned}
$$

En las ecuaciones previas, $k$ representa al $k$-ésimo agente económico. $R$ es su rendimiento, $x_{k}$ es la participación del agente en el rendimiento del Portfolio Sharing $\left(R_{p}\right)$, mientras que $\sigma$ representa la desviación estándar o riesgo, $\sigma_{k}(R)$ el riesgo del agente económico y $\sigma\left(R_{p}\right)$ el riesgo de la cartera de mercado. $E$ es el operador de expectativas.

Debido a que algunos agentes tomarán posiciones cortas y otros serán sus contrapartes, esta situación lleva a que la posición neta del mercado sea nula respecto de los préstamos. Lo antedicho conduciría a que la cartera de mercado sea la cartera óptima; los agentes sólo deberían determinar la cantidad de riesgo que desean asumir. La cartera de inversiones de la Portfolio Sharing Company domina a las carteras de los agentes en el sentido de que se obtiene mayor rendimiento para el mismo nivel de riesgo.

\section{Equilibrio con restricción de endeudamiento: Cartera beta-cero}

F. Black (1972) deriva el CAPM sin tasa libre de riesgo: no existe activo libre de riesgo ni endeudamiento a la tasa libre de riesgo. Black trata los dos casos de forma separada: inicia asumiendo que no existe un activo libre de riesgo en el cual se pueda invertir o endeudar; luego plantea el caso en el cual los agentes no pueden endeudarse pero si invertir en el activo libre de riesgo. En ambos casos la relación lineal planteada en el CAPM, entre riesgo y rendimiento, se sigue cumpliendo.

Black proyecta un modelo donde trata de determinar si la relación planteada por el CAPM entre rendimiento esperado y riesgo se mantiene. Basado en los trabajos previos de Sharpe (1970) y de Cass y Stiglitz (1970), Black indica que cualquier cartera eficiente puede ser expresada como la combinación ponderada de dos 
carteras básicas. El autor halla la cartera óptima bajo dos restricciones: la primera, es que la cartera debe tener el rendimiento deseado; la segunda, que las participaciones deben sumar la unidad ${ }^{3}$. La solución a las condiciones de primer orden presenta los valores de las participaciones en función de dos carteras básicas; después de cierta manipulación algebraica, se deriva que las carteras eficientes son combinaciones ponderadas de las carteras básicas. Esto es, los coeficientes que relacionan las carteras básicas con la eficiente suman la unidad.

Estas carteras básicas no son únicas, es por ello que a partir de estas se forma otro par de carteras con las cuales también se pueden obtener las demás. A este nuevo par de carteras (llamadas $u$ y $v$ ) se les asigna una característica especial a cada una: la primera tendrá una beta igual a la unidad, mientras que la segunda tendrá una beta nula. Con estas nuevas carteras básicas se halla la participación de cada activo en la cartera de mercado $\mathrm{y}$, después de hacer algunas sustituciones, se muestra que la cartera de mercado debe ser $u$, lo que implica que su beta sea la unidad. Así, las carteras $u$ y $v$ pasan a ser llamadas las carteras de mercado $(m)$ y beta cero $(z)$. Cualquier cartera $k$ puede ser obtenida como una combinación de las carteras $m$ y $z$, por lo que su rendimiento esperado puede ser expresado como sigue:

$$
\begin{gathered}
E\left(R_{k}\right)=\beta_{k} E\left(R_{m}\right)+\left(1-\beta_{k}\right) E\left(R_{z}\right) \\
E\left(R_{k}\right)=E\left(R_{z}\right)+\beta_{k}\left[E\left(R_{m}\right)-E\left(R_{z}\right)\right]
\end{gathered}
$$

La relación entre el rendimiento esperado de la cartera eficiente $k$ y su beta sigue siendo lineal, exista o no activo libre de riesgo. Si este existe, el intercepto será la tasa libre de riesgo; si no existe, el intercepto es el rendimiento esperado de la cartera beta cero: $E\left(R_{z}\right)$. Black señala que la ecuación anterior se aplica tanto a activos como a carteras.

Black resalta que cualquier cartera con beta igual a cero debe tener un rendimiento esperado igual al de la

3 Debe quedar claro que se está minimizando el riesgo (la varianza). cartera $z$. El rendimiento de la cartera $z$ es independiente del rendimiento correspondiente al de la $m$. Ya que las carteras eficientes son combinaciones ponderadas de la $m$ y la $z, z$ debe ser la cartera de mínima varianza de todas las carteras beta cero ${ }^{4}$.

Al comentar el artículo de Fama, Black señala que el rendimiento esperado del portafolio $k$ no es consistente con el equilibrio de mercado. Si $\beta_{k}$ es menor a la unidad y suponiendo que $E\left(R_{z}\right)$ es positivo, la participación en el Portfolio Sharing (ecuación 1$)$ será menos atractiva que la cartera eficiente (ecuación 4). Si $E\left(R_{z}\right)$ es negativo y $\beta_{\mathrm{k}}$ es mayor a la unidad, las participaciones en el Portfolio Sharing serán menos rentables que las inversiones en la cartera eficiente. Black señala que las participaciones en el Portfolio Sharing no serán vendidas, excepto cuando se puede obtener un número tal que la tasa libre $\left(R_{f}\right)$ conlleve a que en la ecuación (4) los esperados sean iguales a los realizados y, por consiguiente, la tasa de rendimiento de la cartera beta cero sea igual a la de la cartera de libre de riesgo.

La crítica de Black al artículo de Fama no tiene fundamentos válidos. En esencia, ambos investigadores modelan las carteras tangente como las carteras de mercado. Cuando existe un activo libre de riesgo, la frontera eficiente es una recta. En el caso de Fama, se trata de hacerlo mediante la determinación de un punto y la pendiente. Por su parte, Black lo hace a través de la cartera tangente y la tasa libre de riesgo. En otras palabras, son dos modos de definir una misma recta. La diferencia entre un modelo y otro está en la forma cómo expresan la frontera eficiente. Para Fama, beta es una proporción de la cartera tangente; para Black, beta representa la pendiente de la recta que une la tasa libre de riesgo con la cartera tangente. En el modelo de Fama, beta no puede ser mayor a la unidad tal como lo plantea Black en su crítica.

El siguiente caso que trata Black es un modelo en el que existe un activo libre de riesgo en el cual se puede

4 La covarianza entre las carteras $m$ y $z$ es cero, por ser independientes; esto implica que el coeficiente beta en el modelo CAPM será nulo. Es directo inducir porque toma su nombre. 
invertir, pero no se puede tomar posiciones cortas. La principal restricción es que la proporción de los bonos libres de riesgo en la cartera de inversión sea positiva: no se coloca ninguna restricción con respecto de los demás activos. La condición de equilibrio impone que el rendimiento esperado de la cartera beta cero sea mayor a la tasa libre de riesgo y menor al rendimiento esperado del mercado. Al igual que en el caso anterior, cuando existe la posibilidad de invertir en activos libres de riesgo pero los agentes no pueden endeudarse a la tasa libre de riesgo, la relación entre el rendimiento esperado y el riesgo debe ser lineal.

\section{Estimación de la frontera eficiente sin restricción}

A diferencia de las estimaciones anteriores, en la frontera eficiente estimada en este documento sí se permiten las operaciones en corto. Las administradoras podrían reproducir los resultados de una posición corta a través de una estrategia adecuada. Una buena explicación del marco teórico para el manejo de derivados y la obtención de las posiciones cortas o largas puede encontrarse en Stoll y Whaley (1993); también se puede consultar Fabozzi (2004).

Bajo el marco definido, la restricción más importante impuesta a la estimación de la frontera fue que sus participaciones respecto del valor total de la cartera sumarán la unidad. Con la finalidad de dejar establecidas claramente las condiciones bajo las cuales se deriva la frontera eficiente, previamente mencionaremos algunos supuestos bajo los cuales se obtiene. El primer supuesto es que no existen fricciones ni restricciones en el mercado. El segundo es que no existen impuestos. El tercer supuesto es que los agentes pueden tomar posiciones cortas o construir estrategias que permitan reproducir estas posiciones. El cuarto supuesto dice que existe endeudamiento a la tasa libre de riesgo; en ese sentido, tomar una posición corta con bonos a la tasa libre de riesgo puede considerarse como endeudamiento mientras que comprar estos bonos equivale a prestar a la tasa libre de riesgo. El quinto supuesto señala que existe una tasa libre de riesgo la cual puede ser no observable; esta tasa no será utilizada para la derivación de la frontera, pero se utilizará más adelante para la evaluación del desempeño de las administradoras. Con estos supuestos se puede derivar la frontera eficiente, por lo que, si se necesitan supuestos adicionales, se establecerán conforme se requieran. Queda claro que algunos supuestos usuales se cumplen ${ }^{5}$ : los mercados son competitivos, los agentes son tomadores de precios. Estos supuestos impiden que las operaciones de las AFP puedan influir en el precio de mercado.

La frontera eficiente representa todas aquellas combinaciones de puntos que reflejan la menor varianza posible para un nivel dado de rendimiento esperado. Alternativamente, puede definirse como todos aquellos puntos en los cuales se obtiene un rendimiento óptimo dado un nivel de riesgo. En esta segunda definición, óptimo puede entenderse como máximo o mínimo, lo que permite que esta definición obtenga los mismos puntos de la primera; típicamente, la curva sólo se utiliza en su parte superior (carteras eficientes) que viene determinada por el punto de mínima varianza; esto es, los punto de rendimiento deseado por debajo del rendimiento esperado correspondiente a la mínima varianza de la frontera eficiente son desechados.

Tabla 1.

Activos de la cartera de inversiones

\begin{tabular}{cl}
\hline Activo & \multicolumn{1}{c}{ Nombre } \\
\hline 1 & Bonos del Gobierno \\
2 & Certificados de Depósito del BCRP (CD- BCRP) \\
3 & Bonos Corporativos \\
4 & Acciones Domésticas \\
5 & Depósitos en Moneda Nacional \\
6 & Depósitos en Moneda Extranjera \\
7 & Inversiones en el Exterior: Acciones \\
8 & Inversiones en el Exterior: Bonos \\
\hline
\end{tabular}

Para la determinación de la frontera eficiente se seguirá a Merton (1972), quien ya la derivó cuando se cuenta con tres o más activos ${ }^{6}$. La frontera eficiente

5 Supuestos adicionales sobre el comportamiento de los agentes se pueden consultar en Tobin (1958).

6 En sentido estricto, la notación utilizada en la ecuación siguiente corresponde a la utilizada por Campbell, Lo y MacKinlay (1997), quienes desarrollaron su texto en LaTeX; el texto de Merton (1972) fue mecanografiado. 
se obtiene de las carteras que satisfacen la siguiente optimización restringida:

$$
\underset{\omega}{\operatorname{Min}} \omega^{\prime} \Omega \omega
$$

sujeto a:

$$
\begin{gathered}
\omega^{\prime} \mu=\mu_{p} \\
\mu^{\prime} \iota=1
\end{gathered}
$$

En la optimización anterior, $\omega$ representa el vector de participación de los activos en la cartera de inversión; $\Omega$ representa la matriz de varianzas y covarianzas. La optimización se realiza con respecto del vector de participaciones $\omega$. Los activos que describen el contenido del vector de participaciones $\omega$ están descritos en la Tabla 1.

La cartera de mínima varianza se obtiene cuando el rendimiento es $13.3916 \%$ y el riesgo $2.2207 \%$ (la varianza correspondiente es de $0.0493 \%$ ). Esta cartera se obtiene bajo el supuesto de que no existe activo libre de riesgo; si éste existiera, la frontera sería una recta ${ }^{7}$ Merton (1972). Campbell, Lo y MacKinlay (1997) señalan que todas las carteras eficientes serían una combinación de la cartera tangente y la inversión en la tasa libre de riesgo. En ese sentido, entonces, todas las carteras con rendimientos menores a la de mínima varianza deben ser descartadas. En la Tabla 2 mostramos las estadísticas básicas de la información utilizada.

Tabla 2.

Estadísticas básicas (Porcentajes)

\begin{tabular}{lrrc}
\hline \multicolumn{1}{c}{ Activo } & Media & Desv. Est. & $\begin{array}{c}\text { Rendimiento / } \\
\text { Riesgo }\end{array}$ \\
\hline Bonos del Gobierno & 10.405 & 8.145 & 1.277 \\
CD-BCRP & 13.147 & 4.936 & 2.633 \\
Bonos Corporativos & 12.197 & 4.271 & 2.855 \\
Acciones Domésticas & 13.770 & 31.378 & 0.439 \\
Depósitos MN & 15.448 & 6.192 & 2.495 \\
Depósitos ME & 11.278 & 8.033 & 1.404 \\
Acciones exterior & 18.989 & 24.078 & 0.789 \\
Bonos exterior & 11.533 & 7.432 & 1.552 \\
\hline
\end{tabular}

La cartera de mínima varianza contiene algunas participaciones negativas, esto implica que se debe tomar posiciones cortas en esos activos. La regulación impide a las administradoras tomar posiciones cortas en los activos, pero sí les permite incluir opciones en sus

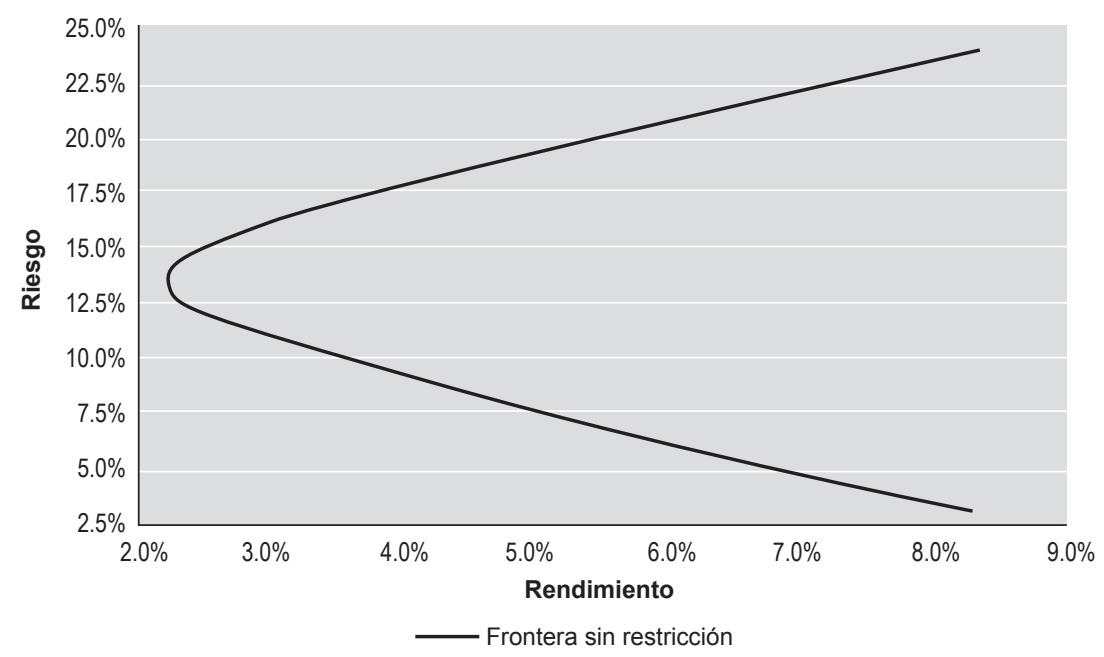

Figura 1. Frontera eficiente: 1995-2004.

Fuente: Pereda (2007). Elaboración: Propia.

7 Las ramas de la parabólica se convierten en rectas y la recta inferior es ignorada. 
inversiones. En una cartera con un activo riesgoso y el libre de riesgo, si el rendimiento del activo riesgoso fuera menor a la tasa libre de riesgo, entonces debería tomarse una posición corta en el activo con riesgo. Cuando no existe activo libre de riesgo, la decisión de tomar una posición corta no dependerá sólo del rendimiento del activo, sino también influirá el riesgo y el coeficiente de correlación como se verá más adelante.

Tabla 3

Composición de la cartera de mínima varianza

(porcentual, respecto del valor de la cartera)

\begin{tabular}{clc}
\hline Activo & Nombre & Participación \\
\hline 1 & Bonos del Gobierno & -5.8761 \\
2 & Certificados de Depósito & 52.5228 \\
& (CD-BCRP) & 50.2182 \\
3 & Bonos Corporativos & 7.9192 \\
4 & Acciones Domésticas & 12.3298 \\
5 & Depósitos en Moneda Nacional & -54.3280 \\
6 & Depósitos en Moneda & \\
& Extranjera & -2.4619 \\
7 & Inversiones en el Exterior: & 39.7661 \\
8 & Acciones & Inversiones en el Exterior: \\
& Bonos
\end{tabular}

La frontera eficiente fue estimada en $\mathrm{Matlab}^{8}$, mientras que la cartera de mínima varianza fue estimada en una hoja de cálculo aplicando las fórmulas derivadas por Merton (1972). La Figura 1 muestra la frontera eficiente. En la Tabla 3 se muestra la composición de la cartera de mínima varianza. Se aprecia que en la cartera de varianza mínima algunos activos tienen participación negativa; esto implica que se está tomando posiciones cortas en Bonos del Gobierno, Depósitos en ME y Acciones del Exterior. En este grupo de activos resalta el hecho de que las Acciones del Exterior son los activos con mayor rendimiento.

\section{EL IMPACTO DE LAS REGULACIONES}

En esta sección se evalúa el impacto sobre la frontera eficiente que ejercen las restricciones impuestas por

8 Matlab es un producto de The Math Works, Inc. los reguladores. Estas restricciones serán introducidas en dos etapas: en la primera se considerará el impedimento que existe a las posiciones cortas. En la segunda etapa se impondrán los límites de inversión sobre las diferentes categorías de valores en las que pueden invertir las administradoras. Asimismo, se analizará si los criterios utilizados por los reguladores para limitar las inversiones, entre las diversas categorías de activos, tuvieron como objetivo disminuir la exposición al riesgo máximo o forzar a las administradoras a mantener adecuados balances entre rentabilidad y riesgo en sus carteras. Un aspecto concomitante, en cuanto al impacto de las restricciones, es la medición cuantitativa que éstas tuvieron en el desempeño de las administradoras, tema que será evaluado en la siguiente sección.

\section{Frontera eficiente sin posiciones «cortas»}

El efecto más saltante de la existencia de restricciones a las posiciones cortas es el incremento del riesgo mínimo; éste paso de $2.2207 \%$ a $3.1118 \%{ }^{9}$. Se debe precisar que en este escenario el rendimiento de la cartera deberá ubicarse entre los correspondientes a los activos de mayor y menor rendimiento; el riesgo máximo correspondería al del activo más riesgoso, mientras que el riesgo mínimo está determinado por las correlaciones de los activos de la cartera. El activo menos riesgoso corresponde a los Bonos Corporativos con un nivel de $4.2714 \%$, mientras que la cartera de mínimo riesgo tiene un nivel de $3.1118 \%$.

En la Figura 2 se distingue el impacto de la imposición de restricciones a la venta en corto. El efecto no sólo ha sido un desplazamiento de la curva, sino que también ha variado ligeramente su curvatura. El cambio de la curvatura implica necesariamente que la cartera tangente tendrá otro nivel de riesgo.

Como se observa en la Tabla 4, la restricción a las posiciones cortas ha llevado a que sean cuatro los activos que componen la cartera de mínima varianza. Los activos

9 Como información peculiar resaltamos que la rentabilidad para estos niveles de riesgo disminuyó de 13.3916 a 13.0055 por ciento. 
Tabla 4.

Composición de la cartera de mínima varianza (Porcentual respecto del valor de la cartera sin posiciones cortas)

\begin{tabular}{clc}
\hline Activo & \multicolumn{1}{c}{ Nombre } & Participación \\
\hline 1 & Bonos del Gobierno &.-- \\
2 & Certificados de Depósito & 43.635 \\
& (CD-BCRP) & \\
3 & Bonos Corporativos & 40.787 \\
4 & Acciones Domésticas & 7.030 \\
5 & Depósitos en Moneda Nacional & 8.548 \\
6 & Depósitos en Moneda Extranjera &.-- \\
7 & Inversiones en el Exterior: &.-- \\
& Acciones &.-- \\
8 & Inversiones en el Exterior: & \\
& Bonos
\end{tabular}

con participación negativa (aquellos en los que se toma posición corta) han desaparecido; la compensación por estos fondos es absorbida casi totalmente por los Bonos del Exterior, cuyas inversiones son ahora nulas. Como veremos más adelante, este hecho está explicado por la alta correlación de los activos eliminados de la cartera y por el bajo rendimiento relativo de algunos de ellos.
La participación de los demás activos se mantienen en proporciones similares a la correspondiente sin limitaciones: los CD-BCRP son las inversiones que absorben la proporción más grande de la cartera, seguida de los Bonos Corporativos. Las Acciones Domésticas y los depósitos en moneda nacional completan la cartera de inversión.

Como puede apreciarse, la disminución de las inversiones en Bonos del Exterior tiene como contrapartida la limitación en las posiciones cortas en depósitos en moneda extranjera. Las Acciones Domésticas han tenido una ligera variación, disminuyeron de $7.9 \%$ a $7.0 \%$. Por su parte, los depósitos en moneda nacional pasaron de $12.3 \%$ a $8.5 \%$. Los CD-BCRP y los Bonos Corporativos disminuyeron $8.9 \%$ y $9.4 \%$, respectivamente ${ }^{10}$.

\section{Frontera eficiente con límites «legales»}

Las restricciones legales implementadas en la estimación de la frontera eficiente son resumidas en la Tabla 5; en este punto seguimos a Pereda (2007). En su trabajo se puede encontrar un buen seguimiento sobre los hechos más importantes referidos a las restricciones legales y modificaciones a las normas sobre fondos de pensiones.

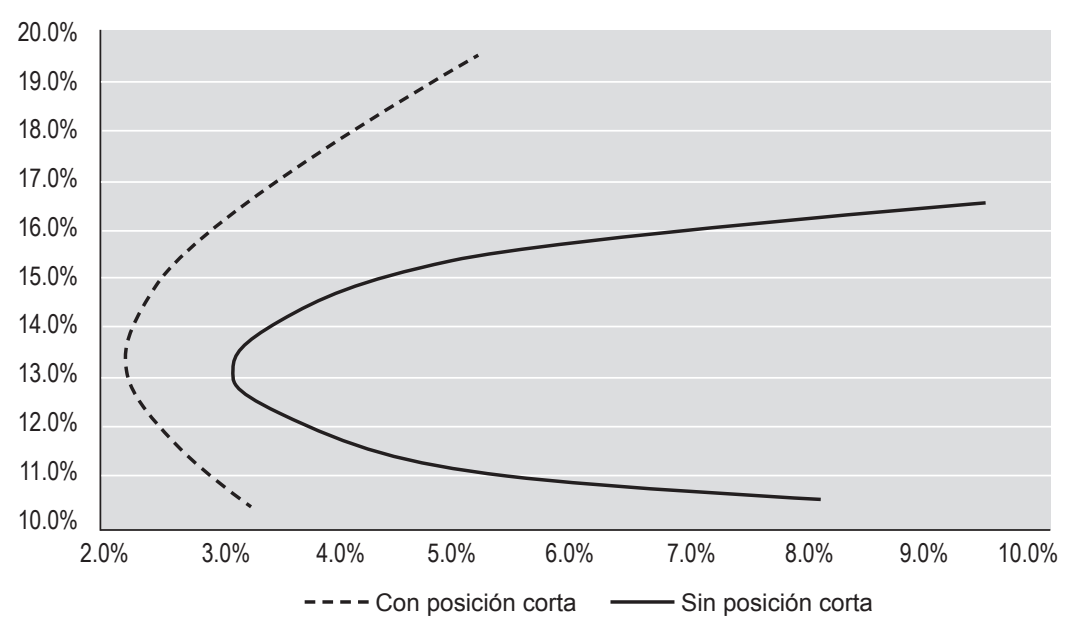

Figura 2. Fronteras eficientes: 1995-2004, con y sin posiciones cortas.

Fuente: Pereda (2007). Elaboración: Propia

10 Los porcentajes de este párrafo son respecto del valor de la cartera de inversión. 
En la frontera eficiente, que incorpora las restricciones legales, el riesgo mínimo llega a 3.1277\%, ligeramente superior al existente con restricción a las posiciones cortas (3.1118\%). Es necesario mencionar que el rendimiento para el mínimo riesgo subió de $13.0055 \%$ a $13.1403 \%$.

Con los límites establecidos en la Tabla 5, la cartera de mínimo riesgo queda compuesta por cinco activos, tal como se aprecia en la Tabla 6. El aspecto más resaltante es que en la cartera, la composición es parecida a los casos anteriores, cuatro activos tienen más del 99\% del valor de la misma; si bien ahora son cinco los activos, la participación de los Bonos del Exterior sólo alcanza el 0.16\%.
En los tres casos estudiados, la cartera de mínimo riesgo ha quedado conformada por un núcleo de cuatro activos, mientras que los otros cuatro casi han sido obviados. Este hecho no es casual. La composición de la cartera de mínimo riesgo está determinada por la correlación de los activos y por su rendimiento individual, tal como apreciaremos en la siguiente sección. El análisis de las carteras de mínimo riesgo nos dará algunos indicadores sobre cómo se correlacionan los activos que contendrán las carteras óptimas y algunas luces sobre lo que motiva que determinados activos no se consideren dentro de las carteras eficientes.

Tabla 5.

Restricciones legales a las inversiones de los fondos de pensiones (Porcentual respecto del valor del fondo)

\begin{tabular}{lcc}
\hline \multicolumn{1}{c}{ Activo } & Restricción & Tipo \\
\hline Bonos del Gobierno & Máximo 30.0\% & Individual \\
Certificados de Depósito (CD-BCRP) & Máximo 30.0\% & Individual \\
Bonos del Gobierno y Certificados de Depósito (CD-BCRP) & Máximo 40.0\% & Conjunta \\
Acciones Domésticas & Máximo 35.0\% & Individual \\
Depósitos en Moneda Nacional y Depósitos en Moneda Extranjera & Máximo 30.0\% & Conjunta \\
Acciones del Exterior y Bonos del Exterior & Máximo 10.5\% & Conjunta \\
\hline
\end{tabular}

Tabla 6

Composición de la cartera de mínima varianza.

(Porcentual respecto del valor de la cartera con límites legales)

\begin{tabular}{clc}
\hline Activo & \multicolumn{1}{c}{ Nombre } & Participación \\
\hline 1 & Bonos del Gobierno &.-- \\
2 & Certificados de Depósito (CD-BCRP) & 30.000 \\
3 & Bonos Corporativos & 46.077 \\
4 & Acciones Domésticas & 6.749 \\
5 & Depósitos en Moneda Nacional & 17.015 \\
6 & Depósitos en Moneda Extranjera &.-- \\
7 & Inversiones en el Exterior: Acciones &.-- \\
8 & Inversiones en el Exterior: Bonos & 0.159 \\
\hline
\end{tabular}




\section{Los límites legales}

La última columna de la Tabla 2 es un primer indicador sobre el aporte de los activos a la composición de la cartera óptima. En esta columna se muestra la relación entre el rendimiento y el riesgo de cada activo; es decir, se muestra el rendimiento otorgado por cada uno de los activos por unidad de riesgo individual. En esta perspectiva, mayor riesgo debería implicar mayor rendimiento, por lo que la última columna podría representar una aproximación para la selección de activos al elegir aquellos que otorgan mayor rendimiento por unidad de riesgo. Como primer indicador, este ratio no describe el panorama completo; lo determinante para la incorporación de un activo a la cartera es el aporte que realiza al riesgo de la cartera, por lo que el riesgo individual no es el relevante. Es decir, se debe mirar la correlación con los otros activos por lo que, a pesar de tener un bajo ratio de rendimiento respecto del riesgo, el activo puede ser incorporado a la cartera. En el Anexo A se muestra la matriz de correlación entre los activos.

En esta sección analizamos los límites legales impuestos por el regulador. Se evalúa cómo estas restricciones afectan la cartera de riesgo mínimo. Luego de medir el impacto de las medidas sobre el riesgo mínimo, se analiza si los efectos se extendieron hacia la cartera óptima; esto permitirá apreciar mejor un aspecto que es ligeramente más complicado

\section{Limite a las inversiones conjuntas en Bonos del Gobierno y Certificados del BCRP}

Si la cartera estuviera compuesta por Bonos del Gobiernos y los Certificados de Depósito del BCRP (CD$\mathrm{BCRP}$ ), en ausencia de posiciones cortas, la frontera eficiente de inversión está representada por la línea intermedia (continua) de la Figura 3-a. La frontera eficiente tiene pendiente negativa. La forma y posición de la frontera está determinada por dos factores: la correlación entre ambos instrumentos de inversión y el rendimiento de los activos.
El punto A representa una cartera con inversión total en los Certificados de Depósito (CD-BCRP); el punto $\mathrm{B}$ representa la cartera con inversión total en Bonos del Gobierno. En el punto A el rendimiento es $13.1 \%$ y el riesgo asciende a $4.9 \%$. En el punto $\mathrm{B}$, el rendimiento y el riesgo son $10.4 \%$ y $8.1 \%$, respectivamente. En estas circunstancias, resulta claro que mayores niveles de inversión en los Bonos del Gobierno resultarán en menor rentabilidad sin una disminución significativa del riesgo; el punto $\mathrm{C}$ representa el de mínimo riesgo con rendimiento y riesgo de $12.4 \%$ y $4.4 \%$ respectivamente. Si la correlación fuera +1 , la frontera sería una recta, la línea a la derecha (punteada). En este caso, mayores niveles de inversión en Bonos del Gobierno conllevarían mayores niveles de riesgo y menores de rentabilidad, por lo que se debe evitar colocar instrumentos financieros con un alto valor de correlación (cercano a +1 ) en una misma cartera. El trazo izquierdo (discontinuo) representa una cartera hipotética de los dos activos mencionados, pero teniendo una correlación de -0.9 . Si la correlación hubiera sido -1 , el punto $C$ habría tocado el eje de las ordenadas en la tasa libre de riesgo y los tres puntos habrían formado un triángulo. Se debe resaltar que, con correlación negativa perfecta, el riesgo puede ser eliminado, por lo que su rendimiento debe ser la tasa libre de riesgo, aunque ésta no se negocie en un instrumento; de tener un rendimiento diferente se presentarían oportunidades de arbitraje.

Es importante mencionar que en el punto de mínimo riesgo la participación de esta cartera hipotética implica $24.6 \%$ para los Bonos de Gobierno y $75.4 \%$ para los CD BCRP. Poner un tope máximo a las participaciones limita obtener los niveles máximos de rentabilidad. Al ser la correlación positiva, los riesgos no se limitan, sino lo contrario, se pueden estar incrementando. Esto se observa en la línea de la derecha (punteada). Si se permitieran las posiciones cortas, la frontera eficiente tendría la forma de la curva mostrada en la Figura 3-b. Esta situación, que podría parecer un contrasentido, se explica por el hecho de que riesgos y rendimientos que están «desalineados»: el rendimiento de los CD-BCRP es mayor al de los Bonos del Gobierno y, paralelamente, tiene un menor riesgo. 


\section{Límite a las inversiones en acciones domésticas}

Las inversiones en acciones negociadas en el mercado doméstico tienen un límite de $35 \%$. No obstante ello, se puede apreciar que, cuando no existen restricciones a las posiciones cortas o a límites máximos a los demás activos, su participación es la menor entre las carteras de mínimo riesgo. En las tres situaciones analizadas, las participaciones fueron de $7.9 \%, 7.0 \%$ y $6.7 \%$ del valor total de la cartera para los casos de fronteras sin restricciones, sin posiciones cortas y con los límites legales respectivamente.

Nuevamente, si volvemos la Tabla 2, se verá que las acciones domésticas son las que presentan un mayor riesgo $(31.4 \%)$ y el menor ratio rendimiento a riesgo individual (sólo 0.439). A pesar del bajo nivel del indicador mencionado, su inclusión en la cartera óptima estaría explicada por su correlación negativa con los activos que mayor peso tienen en la cartera: los CD BCRP y los Bonos Corporativos.

La Figura 3-c muestra la frontera eficiente de una cartera hipotética conformada por los CD BCRP y las acciones domésticas (línea continua). La otra línea inferior (discontinua) representa la frontera hipotética conformada por Bonos Corporativos y acciones domésticas.
En los tres casos analizados de carteras de riesgo mínimo, la participación de las acciones domésticas es baja; este hallazgo es consistente con lo hallado por Pereda, donde sus carteras mínimas también tienen una baja participación de acciones domésticas. Aunque no lo hemos mostrado, en nuestras estimaciones de carteras eficientes sin restricciones las participaciones de las acciones domésticas tienen un máximo de 7.9\% hasta participaciones cortas (participación negativa) de $8.1 \%$. Cuando se impiden posiciones cortas, la participación máxima en una cartera eficiente llega al 9.8\% del valor de la cartera; cuando la frontera tiende a sus valores máximos (19.0\% de rendimiento) la participación de las acciones domésticas es nula.

Después de la introducción de los límites legales a los otros activos, la participación de las acciones domésticas se incrementa significativamente. Todas las carteras eficientes contienen participación de las acciones domésticas; éstas varían del 6.7\% al 35.0\% de participación en el valor de la cartera total, se debe resaltar que alcanza el tope de la restricción. Resultados similares halló Pereda, como se indica en la Tabla 4 de su trabajo: la participación de las acciones domésticas varía del $1.0 \%$ al $10.0 \%$ del valor de la cartera; ellas participan en las carteras eficientes $71 \%$

Tabla 7.

Cartera de mínima varianza con rendimiento esperado de $14.7 \%$ (Porcentual respecto del valor total de la cartera)

\begin{tabular}{lrcc}
\hline \multicolumn{1}{c}{ Activo } & Sin restricción & Sin posición corta & Límites legales \\
\hline Bonos del Gobierno & -13.483 &.-- &.-- \\
CD-BCRP & 29.522 &..- & 24.500 \\
Bonos Corporativos & 78.417 & 18.484 &.-- \\
Acciones Domésticas & 5.927 & 8.766 & 35.000 \\
Depósitos MN & 35.141 & 72.750 & 30.000 \\
Depósitos ME & -85.923 &.-- &.-- \\
Acciones del Exterior & 3.893 &.-- & 10.500 \\
Bonos del Exterior & 46.506 &.-- &.-- \\
Total & 100.000 & 100.000 & 100.000 \\
Riesgo & 2.4366 & 4.0909 & 10.6303 \\
\hline
\end{tabular}



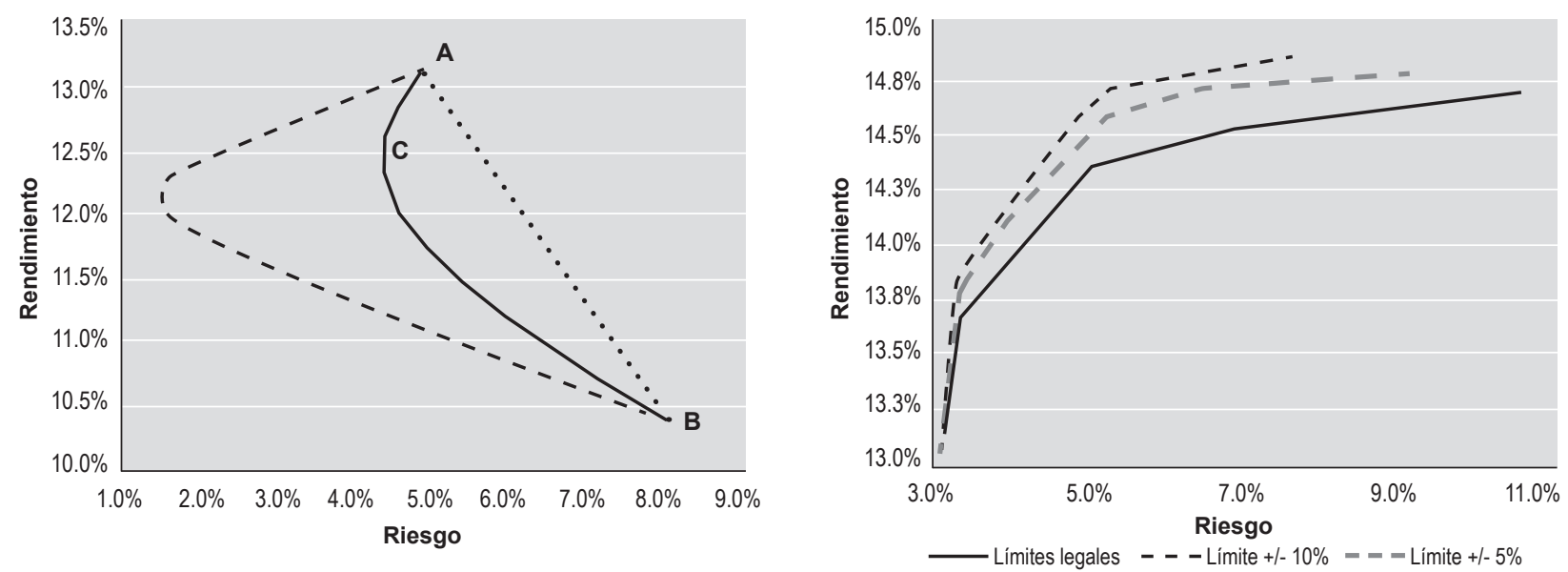

Figura 3-a

Figura $3-d$

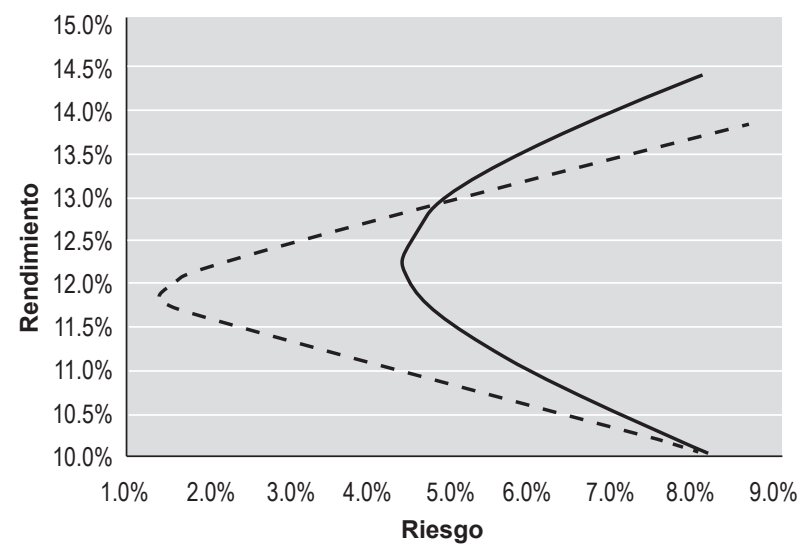

Figura 3-b
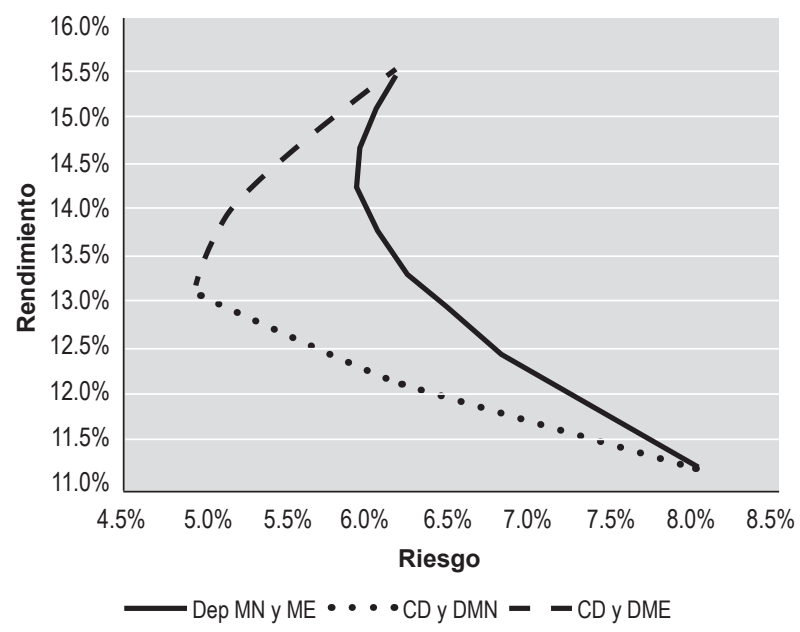

Figura 3-e
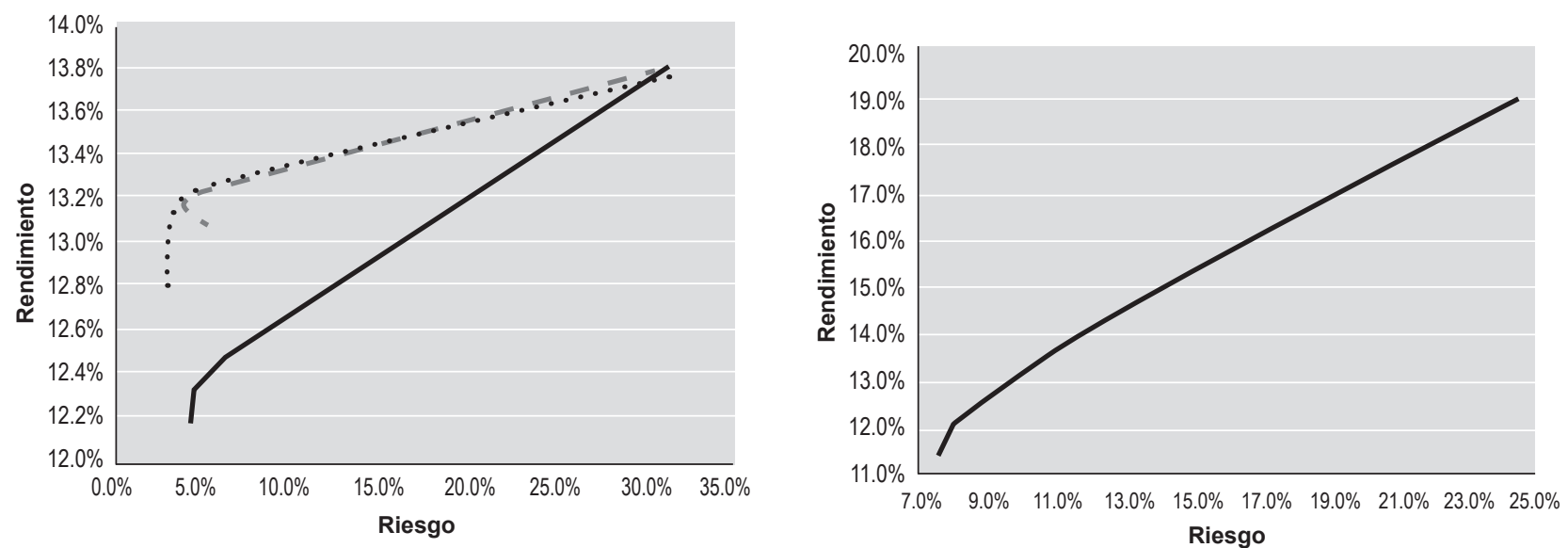

Figura 3-c

Figura 3-f 
de las veces ${ }^{11}$. En la Tabla 5 del trabajo de Pereda se muestra que las acciones domésticas entraron en todas las carteras eficientes, con participaciones que van del $6.7 \%$ al $35.0 \%$.

Un aspecto importante de este estudio es determinar si la regulación contribuyó a disminuir (o limitar) la preferencia por el riesgo de las administradoras de fondos de pensiones. Si se toma en cuenta lo mostrado en la Tabla 7, podemos adelantar que los límites de inversión impuestos validaron las preferencias de las administradoras por el riesgo.

Como mencionamos previamente, el rendimiento de la cartera es una combinación (lineal) de los rendimientos individuales de los activos, mientras que la relación entre el riesgo de la cartera y el de los activos es no lineal. Desde la perspectiva del rendimiento, es imposible encontrar carteras que tuvieran rendimiento esperado mayor al $15.5 \%$ sin que se incluya las acciones del exterior. Desde la perspectiva del riesgo, la situación puede ser marcadamente diferente. Tal como se observa en la Figura 3-d, se puede obtener menores niveles de riesgo con un adecuado establecimiento de los límites de inversión.

La línea inferior (continua) representa las carteras eficientes determinadas de acuerdo con los límites impuestos por el regulador. La línea intermedia (segmentada) representa un conjunto de carteras eficientes con una modificación en los límites de los CD BCRP (límite del 30\% al 35\%), de los depósitos (límite del $30 \%$ al 35\%) y las acciones domésticas (límite del 35\% al 30\%). La línea superior (punteada) representa un conjunto de carteras eficientes con una modificación en los límites de los CD BCRP (límite al 40\%), de los depósitos (límite al 40\%) y las acciones domésticas (límite al 25\%). En el punto de mínima varianza, la línea punteada tiene un riesgo del $3.1128 \%$, mientras que su

11 Se debe aclarar que, desde nuestra perspectiva, la participación mínima es la nula, que coincide con su frecuencia de no participación positiva. Sin contar la participación nula, la más baja que encontramos fue $0.6 \%$. rendimiento es del 13.0396\%. En la línea segmentada, el punto mínimo representa un riesgo y un rendimiento del $3.1180 \%$ y $13.0911 \%$, respectivamente. En el punto mínimo para las carteras estimadas con los límites legales el rendimiento y el riesgo es de $13.1403 \%$ y $3.1277 \%$. Para este nivel de rentabilidad, el riesgo para la curva punteada y la segmentada es de $3.1183 \%$ y $3.1195 \%$, respectivamente. En el Anexo B presentamos la composición de las carteras en los puntos mínimos mencionados. En el Anexo C se muestra la frontera eficiente para los escenarios de la Figura 3-d; en esta figura sólo se muestra las carteras eficientes para una mejor comprensión.

\section{Límite a los depósitos}

Se observa en la Tabla 2 los rendimientos esperados de los depósitos en moneda nacional y extranjera, con niveles del $15.448 \%$ y $11.278 \%$ respectivamente. Si además se toman en cuenta los respectivos riesgos, una primera impresión sería que los depósitos en moneda extranjera tienen un bajo ratio rendimiento riesgo (1.404 para la extranjera, mientras que para la moneda nacional es de 2.495) por lo que no debería incluirse en la cartera óptima. El panorama completo se percibe a través de la elevada correlación que observan los depósitos (en ambas monedas) con los CD BCRP.

La Figura 3-e refleja la situación de los depósitos. La línea continua representa una cartera compuesta por los depósitos en moneda nacional y extranjera, mientras que la línea discontinua representa una cartera compuesta por los depósitos en moneda nacional con los CD BCRP. Tal como se aprecia, esta última cartera otorga mayores rendimientos a menores niveles de riesgo. $\mathrm{La}$ línea punteada representa una cartera compuesta por los depósitos en moneda extranjera con los CD BCRP. La exclusión de los depósitos en moneda extranjera estaría explicada por la elevada correlación que posee con los CD BCRP, lo que permite obtener su desempeño con menores niveles de riesgo. La moneda nacional tiene mayores niveles de rendimiento que la extranjera y su riesgo individual, así como su contribución al riesgo de la cartera, son menores. 


\section{Límite a las inversiones en acciones y bonos del exterior}

El límite máximo para inversiones en estos instrumentos es del $10.5 \%$ del valor de la cartera. Las inversiones en acciones del exterior es el activo que mayor rendimiento individual (18.989\%), pero también es elevado su riesgo (24.078\%). Su elevado rendimiento es lo que explica que, cuando se imponen restricciones solo a las posiciones cortas, ellas conformen casi la totalidad de las carteras de mayor rendimiento.

La Figura 3-f muestra las carteras eficientes conformadas por los bonos y las acciones del exterior. Se aprecia los elevados niveles de rendimiento, su nivel mínimo supera el $11.5 \%$ mientras que su nivel máximo se aproxima a $19.0 \%$. No obstante ello, el aspecto al que se le presta mayor atención es al riesgo. En ninguna de las figuras previas se ha observado que el nivel de riesgo se aproxime al nivel mínimo de una cartera conformada por bonos y acciones del exterior. Desde un punto de vista de limitación de riesgos, los límites de inversión debieron ser mínimos o casi nulos. Si bien lo determinante para incorporarlos a la cartera es su contribución al riesgo global de la misma, las correlaciones que presentan con otros activos son elevadas: 0.7 y 0.9 de coeficientes de correlación de las acciones y bonos del exterior con los depósitos en moneda extranjera; $0.5 \mathrm{y}$ 0.7 de coeficientes de correlación de los mismos con los CD BCRP. El alto coeficiente de correlación de los bonos del exterior con los depósitos en moneda extranjera implica que este último pueda ser tomado como un sustituto (casi) perfecto. Para efectos de formación de carteras, ellos serían como dos activos iguales cuando no se puede adoptar posiciones cortas.

\section{DIFERENCIAS METODOLÓGICAS CON LOS ESTUDIOS PREVIOS}

En estudios previos se midió el efecto de las regulaciones como la diferencia entre los puntos de la frontera con y sin restricciones legales. En este trabajo se trata de medir el efecto como la diferencia entre el Índice de Sharpe obtenido y el máximo posible. Para utilizar el mencionado índice se ha estimado una tasa libre de riesgo para la economía estudiada. En esta sección también compararemos los efectos de la regulación sobre la rentabilidad de los fondos utilizando los criterios indicados en los trabajos de Rivas-Llosa y Camargo (2002) y de Pereda y los efectos medidos por el índice de Sharpe.

\section{La cartera cero-beta y la tasa libre de riesgo}

En nuestra economía hipotética hemos estimado los riesgos para dos valores de tasas de interés siguiendo los lineamientos establecidos por Black (1971). En esencia, calculamos la pendiente para una serie de tasas de interés; luego se halló el intercepto generado por la recta tangente y se calculó el riesgo correspondiente para este nivel de tasa de interés. También se verificó que las carteras estuvieran no correlacionadas.

Bajo el procedimiento anterior, se estimó que la tasa libre de riesgo de esta economía era del $11.87 \%$. Como contrapartida se estimó que la tasa de rendimiento para la cartera de mercado era $14.91 \%$. En el primer caso, el riesgo fue del $2.50716 \%$, mientras que en el segundo caso el riesgo fue $2.50717 \%{ }^{12}$.

Dado que las estimaciones se realizan sobre una economía simplificada, la tasa de interés libre de riesgo podría no ser exactamente la que corresponde a la realidad. No obstante, debemos resaltar que, bajo el supuesto que lo fuera, los activos con rendimiento esperado menor a la tasa libre de riesgo no forman parte de ninguna cartera eficiente. Así, los Bonos del Gobierno, los Depósitos en moneda extranjera y los Bonos del exterior, con rendimientos de 10.4\%, 11.3\% y $11.5 \%$, respectivamente, no se incluyen en ninguna cartera eficiente ${ }^{13}$.

12 En este punto debemos mencionar que la estimación tuvo dos problemas: el primero fue que existía un mínimo local cercano. El segundo fue que trabajar con más de 7 decimales generaba problemas al calcular la derivada.

13 Confróntese con la Tabla 4 en el trabajo de Pereda. 


\section{Evaluación de la cartera: El rendimiento}

En el trabajo de Pereda se midió el efecto de la regulación como la diferencia entre los riesgos realizado y óptimo dado un nivel de rendimiento obtenido. Aquí ampliamos esta perspectiva al incluir los efectos de variaciones en los niveles de restricción de inversión en algunos activos individuales. Como se apreciará, los efectos de la regulación han sido carteras con más riesgo del necesario.

Bajo el supuesto que los rendimientos estimados por Pereda son los efectivamente realizados por los fondos de pensiones, y teniendo en cuenta la composición histórica de las inversiones, calculamos los rendimientos obtenidos en cada período. El resultado fue un rendimiento del $14.07 \%$ en promedio; el riesgo fue del $9.99 \%$. Fijado el rendimiento, se calculó cuál sería el mínimo riesgo con el mencionado rendimiento para las siguientes fronteras eficientes: (a) sin restricciones a las posiciones cortas, lo que permite utilizar las fórmulas Merton; (b) con restricciones a las posiciones cortas; (c) con las restricciones legales utilizadas por Pereda; (d) incrementos del 5\% en los límites a las inversiones en los $\mathrm{CD}-\mathrm{BCRP}^{14}$ y en los depósitos, con una disminución del 5\% en el límite a las inversiones en acciones domésticas; y (e) incrementos del 10\% en los límites a las inversiones en los CD-BCRP y en los depósitos, con una disminución de $10 \%$ en el límite a las inversiones en acciones domésticas.

Como se observa en la Tabla 8, las restricciones impuestas por el regulador han generado carteras más riesgosas. Si bien lo relevante, al momento de fijar las restricciones individuales, no es el riesgo de cada activo sino su correlación con los demás (aporte al riesgo de cartera), la legislación ha favorecido la elevación de los límites de activos que incrementan el riesgo de la cartera y restringido la participación de aquellos que lo disminuyen. H. Campodónico (2008a, 2008b) señala que los niveles de riesgo permitidos por la legislación peruana son elevados respecto de lo permitido por otros países y plantea una reducción drástica. Este ejercicio reforzaría su planteamiento.

Resaltamos que en nuestro último escenario, el riesgo se encuentra más cerca del nivel que se obtendría sin límites máximos que al nivel impuesto por el regulador. Los niveles de inversión en acciones domésticas son bajas en carteras óptimas; no se ve limitada por su restricción de inversión, por lo que una disminución por parte de regulador no hubiera afectado el rendimiento

Tabla 8.

Riesgo mínimo para un rendimiento de $14.1 \%$.

(Porcentual, respecto del valor de la cartera)

\begin{tabular}{lrcrrr}
\hline \multicolumn{1}{c}{ Activo } & Merton & Sin posición corta & Límites legales & $+/-5 \%$ & $+/-10 \%$ \\
\hline Riesgo & 2.28 & 3.49 & 4.35 & 3.99 & 3.76 \\
Bonos del Gobierno & -9.82 &.-- &.-- &.-- &.-- \\
CD-BCRP & 40.57 &.-- & 30.00 & 35.00 & 40.00 \\
Bonos Corporativos & 64.84 & 38.56 & 24.66 & 17.24 & 9.82 \\
Acciones Domésticas & 6.89 & 7.42 & 8.22 & 8.89 & 9.56 \\
Depósitos MN & 24.12 & -7.02 &.-- & 35.00 & 40.00 \\
Depósitos ME & -70.69 &.-- & 7.12 &.-- &.-- \\
Acciones del Exterior & 0.83 &.-- &.-- & 3.87 & 0.62 \\
Bonos del Exterior & 43.26 & 100.00 & 100.00 &.-- &.-- \\
Total & 100.00 & & & 100.00 & 100.00 \\
\hline
\end{tabular}

14 En un primer momento se levantó la restricción a los Bonos del Gobierno, pero resultó inefectiva. 
óptimo. Al contrario, hubiera forzado a las administradoras a disminuir su exposición al riesgo. El incremento de los niveles límite de inversión en los CD-BCRP y en los depósitos requiere de una mayor participación de las acciones domésticas en las carteras óptimas. Esta situación aparentemente contradictoria se debe a que la correlación de las acciones con los dos instrumentos mencionados es negativa; obsérvese que con límites del $10 \%$ hubiera sido suficiente.

\section{Evaluación de la cartera: el riesgo}

Una segunda forma para medir los efectos de la regulación fue calcular la diferencia entre el rendimiento óptimo con y sin la existencia de la regulación, con un nivel de riesgo fijo. La diferencia entre el óptimo, según las restricciones legales, y el rendimiento obtenido es atribuida a los gestores de las administradoras; en otras palabras, es una pérdida generada por inversiones inadecuadas.

En la Tabla 9 se aprecia que los niveles de riesgo utilizados en este documento son elevados. Por un lado, los niveles de apalancamiento, mostrados en un escenario donde no existen limitaciones a las posiciones cortas, indican que el nivel de riesgo obtenido es elevado; también lo es el rendimiento que llega a 26.1\%. De otro lado, cuando los activos más riesgosos -es decir, las acciones domésticas y del exterior con $31.4 \%$ y $24.1 \%$ de volatilidad, respectivamente- son limitados y se relajan los límites de otros instrumentos, este nivel de riesgo es inalcanzable. Ambos indicadores muestran que el nivel de riesgo estimado es excesivamente elevado para cualquier cartera eficiente.

El impacto de la imposición de los límites legales ha provocado una disminución del $1.95 \%$ respecto de una situación sin posiciones cortas y de $11.44 \%$ respecto del escenario en que se permiten posiciones cortas. Esta última diferencia es reflejo del elevado nivel del riesgo que se estaría imponiendo a las carteras de los fondos de pensiones en estas circunstancias.

\section{Evaluación del desempeño}

En esta sección se mide la eficiencia de las inversiones realizadas por las administradoras de fondos de pensiones. El indicador que utilizamos es el Índice de Sharpe. Este índice requiere de una tasa libre de riesgo. Esta tasa libre de riesgo utilizada es $11.87 \%$, estimada previamente como la tasa de rendimiento de la cartera cero-beta. El índice se obtiene al dividir el exceso de

Tabla 9.

Rendimiento máximo dado un riesgo de $10 \%$.

(Porcentual, respecto del valor de la cartera de inversión)

\begin{tabular}{|c|c|c|c|c|c|}
\hline Activo & Merton & Sin posición corta & Límites legales & $+/-5 \%$ & $+/-10 \%$ \\
\hline Rendimiento & 26.10 & 16.61 & 14.66 & n. a. ${ }^{1}$ & n. a.* \\
\hline Bonos del Gobierno & -79.74 &.- &.- &.-- &.-- \\
\hline CD-BCRP & -170.51 &.-- & 26.67 &.-- &.- \\
\hline Bonos Corporativos & 324.17 &.-- &.-- &.-- &.-- \\
\hline Acciones Domésticas & -11.44 &.-- & 32.83 &.-- &.- \\
\hline Depósitos MN & 234.53 & 67.29 & 30.00 &.-- &.-- \\
\hline Depósitos ME & -361.59 &.-- &.- &.-- &.- \\
\hline Acciones del Exterior & 59.29 & 32.71 & 10.50 &.-- &.-- \\
\hline Bonos del Exterior & 105.29 &.-- &.-- &.-- &.- \\
\hline Total & 100.00 & 100.00 & 100.00 &.-- &.- \\
\hline
\end{tabular}

* No alcanzable: No existe la cartera óptima que tenga este nivel de riesgo $(10 \%)$. 
Tabla 10.

Índice de Sharpe con tasa libre de riesgo de $11.87 \%$ (La participación es porcentual respecto del valor de la cartera)

\begin{tabular}{lrrrr}
\hline \multicolumn{1}{c}{ Activo } & Sin posición corta & Límites legales & \multicolumn{1}{c}{$+/$ - $\%$} & \multicolumn{1}{c}{+ / $10 \%$} \\
\hline Índice de Sharpe & 0.701892 & 0.528508 & 0.565681 & 0.589396 \\
Rendimiento (\%) & 15.2096 & 13.6390 & 13.8063 & 13.9606 \\
Riesgo (\%) & 4.7580 & 3.3473 & 3.4230 & 3.5469 \\
Bonos del Gobierno &.-- &.-- &.-- &.-- \\
CD-BCRP &.-- & 30.0000 & 35.0000 & 33.7652 \\
Bonos Corporativos & 2.2443 & 30.9697 & 21.1663 & 17.1832 \\
Acciones Domésticas & 9.8574 & 8.2695 & 8.8337 & 9.0516 \\
Depósitos MN & 87.8983 & 30.0000 & 35.0000 & 40.0000 \\
Depósitos ME &.-- &.-- &.-- &.-- \\
Acciones del Exterior &.-- & 0.7608 &.-- &.-- \\
Bonos del Exterior &.-- &.-- & 100.00 & 100.00 \\
Total & 100.00 & 100.00 & - \\
\hline
\end{tabular}

rendimiento sobre la tasa libre de riesgo entre el riesgo de la cartera. Para la cartera de mercado y la cartera cero-beta calculadas previamente implica dividir su diferencia entre la cantidad de riesgo de la cartera de mercado.

Si no existieran restricciones para obtener posiciones cortas, el Índice de Sharpe sería de 1.2112, calculado de acuerdo con lo mencionado previamente. La Tabla 10 muestra el máximo Índice de Sharpe para cada uno de los escenarios analizados; este índice señala lo que se debe pedir como compensación por cada unidad de riesgo asumida por la cartera de inversión. Bajo el supuesto de que el riesgo asumido hubiera sido $10 \%$, la compensación debió ser del 7.02\% adicional a lo obtenido por una inversión libre de riesgo. Si además se tiene en cuenta que la tasa libre de riesgo (estimada en este trabajo) es del $11.87 \%$, con el riesgo asumido, entonces la tasa de rendimiento debió llegar al 18.89\%.

Una de las formas para obtener los rendimientos más altos es darle mayor ponderación, o límites más elevados, a los activos que tienen mayor rendimiento. En nuestro caso son las acciones del exterior (19.0\%), los depósitos en moneda nacional (15.5\%) y las acciones domésticas (13.8\%). Pero, aquí también se encuentran dos de los activos con mayor riesgo individual: las acciones domésticas y del exterior con $31.4 \%$ y $24.1 \%$, respectivamente. La regulación parece haber tenido un sesgo hacia el rendimiento sin tener en cuenta el riesgo.

Como se puede apreciar en la Tabla 10, en las carteras que buscan obtener una relación óptima entre rendimiento y riesgo, la participación de las acciones domésticas es menor al 10\%. Similar es la situación con las inversiones en acciones del exterior que no superan el 1\%. En general, se puede observar que las participaciones óptimas se incrementan debido a la regulación existente. Conforme se observa en las tablas previas, la participación de las acciones del exterior es mayor cuando se derivan las carteras óptimas bajo los límites legales que cuando se realiza bajo cualquier otro escenario.

Se debe resaltar que en el escenario en que no se permiten posiciones cortas, un riesgo del 10\% exigiría un rendimiento del $18.89 \%$. Este sería un rendimiento similar al que se obtendría si se invierte todo en acciones del exterior, pero con un menor riesgo. En un escenario con una variación de hasta el $10 \%$ en los límites uti- 
Tabla 11.

Riesgo mínimo para un rendimiento de $13.4 \%$ (Porcentual respecto del valor de la cartera)

\begin{tabular}{lrccrr}
\hline \multicolumn{1}{c}{ Activo } & Merton & Sin posición corta & Límites legales & $+/-5 \%$ & $+/-10 \%$ \\
\hline Riesgo & 2.22 & 3.17 & 3.17 & 3.17 & 3.17 \\
Bonos del Gobierno & -5.93 &.-- &.-- &..- &.-- \\
CD-BCRP & 52.32 & 27.13 & 27.13 & 27.13 & 27.13 \\
Bonos Corporativos & 50.40 & 40.10 & 40.10 & 40.10 & 40.10 \\
Acciones Domésticas & 7.91 & 7.16 & 7.16 & 7.16 & 7.16 \\
Depósitos MN & 12.41 & 25.61 & 25.61 & 25.61 & 25.61 \\
Depósitos ME & -54.49 &.-- &.-- &.-- &.-- \\
Acciones del Exterior & -2.42 &.-- &.-- &..- &.-- \\
Bonos del Exterior & 39.80 &.-- &.-- &.-- &.-- \\
Total & 100.00 & 100.00 & 100.00 & 100.00 & 100.00 \\
\hline
\end{tabular}

lizados en este trabajo llevarían a que el rendimiento fuere de hasta el $17.76 \%$.

\section{El desempeño histórico}

Señala Pereda (2007) que las administradoras de fondos de pensiones han obtenido un rendimiento promedio del $13.4 \%$ con un riesgo del $7.4 \%$. En nuestro estudio utilizamos el riesgo y el rendimiento que recalculamos (con los rendimientos estimados por Pereda) para cada uno de los períodos, y la participación (de cada uno de los 8 activos) en la cartera histórica de los fondos de pensiones.

La Tabla 11 es el equivalente a la Tabla 8. Cuando el rendimiento es el mencionado (13.4\%), el efecto de las restricciones legales sobre los niveles óptimos de riesgo es nulo. La imposición de límites legales, así como los escenarios planteados, no afectan el nivel de riesgo óptimo debido a que ninguna de las inversiones se ve restringida a su nivel máximo permitido. Esto explica por qué todos los escenarios, a excepción del que se permite tomar posiciones cortas, son iguales: las restricciones no tienen ningún efecto sobre los óptimos. Esto permite inferir que, dado este nivel de rendimiento, la regulación no tuvo ningún impacto sobre el desempeño de las administradoras de fondos de pensiones.
La Tabla 12 es el equivalente a la Tabla 9 y muestra los rendimientos que se obtienen de acuerdo con el nivel de riesgo. Se observa una elevada participación de los activos riesgosos en las carteras de inversión, lo que indica que las carteras tienen un sesgo elevado al riesgo. A diferencia de la Tabla 9, en la Tabla 12 todos los escenarios alcanzan el nivel de riesgo. Resalta el hecho de que la ganancia de rentabilidad es menor a un punto porcentual luego de pasar del $7.4 \%$ de nivel de riesgo al $10 \%$. En el escenario en el que no se permiten posiciones cortas, el rendimiento se incrementa en $0.56 \%$ (56 puntos básicos) y en el que replica los límites legales $0.13 \%$ (13 puntos básicos).

Si se toma en cuenta que el rendimiento y el riesgo fueron del $13.4 \%$ y $7.4 \%$, respectivamente, el rendimiento exigido para este nivel de riesgo en un contexto que no se permiten posiciones cortas debería haber sido $17.06 \%$. Con las restricciones legales consideradas en este trabajo, el rendimiento exigido debería haber llegado al $15.78 \%$; la diferencia de $1.28 \%$ representa la pérdida generada por las regulaciones. La diferencia en rentabilidad que se obtendría de haber formado una cartera eficiente y la realizada por los fondos llega al 2.34\%; el efecto de la regulación ha sido menor a la pérdida generada por una administración no óptima de los fondos de pensiones. 
Tabla 12.

Rendimiento máximo dado un riesgo de $7.4 \%$

(Porcentual respecto del valor de la cartera de inversión)

\begin{tabular}{lrcrrr}
\hline \multicolumn{1}{c}{ Activo } & Merton & Sin posición corta & Límites legales & $+/-5 \%$ & $+/-10 \%$ \\
\hline Rendimiento & 21.73 & 16.05 & 14.53 & 14.71 & 14.82 \\
Bonos del Gobierno & -63.31 &.-- &.-- &.-- &.-- \\
CD-BCRP & 36.25 &.-- & 30.00 & 31.45 & 26.57 \\
Bonos Corporativos & 202.28 &.-- & 6.39 &.-- &.-- \\
Acciones domésticas & -4.03 & 3.45 & 23.11 & 23.05 & 22.93 \\
Depósitos MN & 102.65 & 77.82 & 30.00 & 35.00 & 40.00 \\
Depósitos ME & -261.71 &.-- &.-- &.-- &.-- \\
Acciones del Exterior & 39.65 & 18.74 & 10.50 & 10.50 & 10.50 \\
Bonos del Exterior & 48.22 &.-- &.-- &.-- &.-- \\
Total & 100.00 & 100.00 & 100.00 & 100.00 & 100.00 \\
\hline
\end{tabular}

\section{CONCLUSIONES}

Un aspecto importante de este estudio, y de los previos, es determinar si la regulación contribuyó a disminuir (o limitar) la preferencia por el riesgo de las administradoras de fondos de pensiones. Paralelamente, se estudió el impacto de las regulaciones sobre el rendimiento de los fondos de pensiones. Luego de lo expuesto, se puede afirmar que los límites de inversión impuestos validaron las preferencias por el riesgo de las administradoras.

Empleando información utilizada en el trabajo de Pereda, en el presente artículo se ha realizado la prueba de si los efectos de la regulación implicaron una disminución de los niveles de rentabilidad a costa de la disminución de los niveles de riesgo. Nuestras conclusiones difieren significativamente de las realizadas previamente: los niveles de riesgo de la cartera aumentaron y los niveles de rentabilidad pudieron aumentar si se hubiesen establecido adecuadamente los niveles de inversión máxima de los activos más riesgosos en niveles más bajos que los efectivamente impuestos.

Para medir el desempeño de las administradoras utilizamos el Índice de Sharpe. Este índice requiere la tasa libre de riesgo, la cual se estimó como el rendimiento esperado de la cartera beta cero de nuestra economía simplificada. El valor estimado fue del $11.87 \%$. Sin embargo, este valor es polémico. Kogan, Makarov y Uppal (2006) encuentran que en una economía con mercados incompletos y bajo aversión relativa al riesgo constante (CRRA), la tasa libre de riesgo es relativamente baja. En este sentido, sólo señalaremos que dicha conclusión se derivó para agentes adversos al riesgo por lo que falta extender el resultado a agentes neutros al riesgo, que es como usualmente se valúan los activos financieros.

A pesar de ello, la tasa estimada parece consistente con un escenario donde los Bonos del Gobierno, los depósitos en moneda extranjera y los bonos del exterior no formen parte de ninguna cartera óptima debido a que obtienen rendimiento menor a la tasa libre de riesgo. Por su parte, Rivas-Llosa y Camargo (2002) utilizaron una tasa libre de riesgo del 2.5\%; si la tasa libre de riesgo está subestimada, el Índice de Sharpe estimado será mayor al real, si la tasa libre de riesgo está sobre estimada el Índice de Sharpe será menor al real. Se debe mencionar que Shanken (1996) señala que, bajo condiciones específicas, el rendimiento de la cartera cero-beta debe ser mayor a la tasa de rendimiento de los Bonos del Tesoro norteamericano (T-Bill), la cual es considerada la tasa nominal libre de riesgo. 
Con la tasa libre de riesgo hallada, y asumiendo que el riesgo y la rentabilidad de los fondos de pensiones fueran del $14.1 \%$ y $10.0 \%$, respectivamente (tal como lo recalculamos), la regulación impuesta llevó a que el riesgo se incrementara en $0.86 \%$ para el nivel de rendimiento dado, mientras que la gestión de los fondos llevó a que se incrementara en 5.64\%. Para el nivel de riesgo mencionado $(10 \%)$, la rentabilidad pérdida por causa de la regulación fue del 1.95\%, mientras que la gestión generó una disminución del $0.56 \%$. Esta aparente contradicción entre las formas de medir el impacto de la regulación se debe a que el nivel de riesgo por alcanzar es demasiado elevado; esto se refleja en el hecho de que existen carteras que con menos riesgo pueden obtener la misma rentabilidad, si se limitan los activos con mayor volatilidad; no obstante, el nivel de riesgo se torna inalcanzable. Un indicador más apropiado es el Índice de Sharpe, el cual toma en cuenta el riesgo y la rentabilidad simultáneamente. La pérdida generada en rentabilidad debido a la regulación fue del 1.73\%, mientras que la gestión generó una pérdida del 3.06\%.

Si se toma como rendimiento y riesgo realizados por las administradoras los valores de $13.4 \%$ y $7.4 \%$, la pérdida ocasionada por la regulación fue del 1.28\% mientras que la correspondiente a la gestión fue del $2.38 \%$. Si se minimiza el riesgo dado el rendimiento (de 13.4\%), el impacto de la regulación fue nulo por lo que la gestión generó un incremento en el riesgo de $4.23 \%$. Si se mira el rendimiento máximo, la regulación provocó una caída de $1.52 \%$ (de 16.05 a 14.53\%), mientras que la gestión generó una disminución de $1.13 \%$ en la rentabilidad.

En este documento se ha medido el desempeño promedio de los fondos de pensiones; es evidente que un trabajo posterior sería medir el desempeño individual. Como se ha observado, las administradoras han mostrado una elevada preferencia por el riesgo: el siguiente paso es determinar quienes lo hicieron mejor o de forma más eficiente. Creemos que un siguiente trabajo debe abordar un estudio más detallado sobre las correlaciones, en especial en algunos valores elevados (por ejemplo, 0.9 de los depósitos en moneda extranjera y los bonos del exterior).

Creemos que un estudio más profundo sobre las correlaciones y los riesgos podría llevar a que lo plantado por Campodónico, respecto de una mayor participación de activos de renta fija en la cartera, sea más adecuado desde una perspectiva de optimización de la relación rentabilidad riesgo. Se debe precisar que en nuestro análisis no es posible separar el efecto cambiario en la estimación del rendimiento de los activos en moneda extranjera. Dicha situación se debe a que el premio exigido a los activos en moneda extranjera no es el mismo para los que miden la rentabilidad en la moneda que se cotiza el activo y los que lo hacen en otra moneda. La medida de probabilidad riesgo neutral, y consecuentemente, los premios exigidos (ajustados por el tipo de cambio) no son los mismos.

Agregaremos que la nueva estructura, dispuesta a través de la formación de los multifondos, ha llevado a una mayor participación de las inversiones en valores. Desde la perspectiva de la rentabilidad, ésta se verá incrementada, pero el incremento estará acompañado por un crecimiento mayor al óptimo en el riesgo. Desde la perspectiva del riesgo, menores niveles del mismo (en nuestro ejercicio) requieren menor participación de las inversiones en activos de renta variable y del exterior. 


\section{Referencias}

Black, F. (1972). Capital Market Equilibrium with Restricted Borrowing. The Journal of Business, 45 (3), 444-455.

Black, F., \& M. Scholes (1973). The Pricing of Options and Corporate Liabilities. The Journal of Political Economy, 81 (3), 637-654.

Campodónico, H. (2008a). AFPs: hay demasiada plata en la Bolsa. En el diario La República, Lima, Perú. Obtenido de <http://www.cristaldemira.com>, el 27/10/08.

Campodónico, H. (2008b). Pésima química: Bolsa de Valores e inversiones de AFP. En el diario La República, Lima, Perú. Obtenido de $<$ http://www.cristaldemira. com> el 11/10/08.

Cass, D., \& Stiglitz, J. E. (1970). The Structure of Investor Preferences and Asset Returns, and Separability in Portfolio Allocation: A Contribution to the Pure Theory of Mutual Funds. Journal of Economic Theory, 2, 122-60.

Fabozzi, F. J. (2004). Shorting Using Futures and Options. En F. J. Fabozzi (Ed.), Short Selling: Strategies, Risks and Rewards (pp. 17-36). New Jersey, NJ: John Wiley \& Sons, Inc.

Fama, E. F. (1971). Risk, Return, and Equilibrium. The Journal of Political Economy, 79 (1), 30-55.

Harrison, M. J., \& Kreps, D. M. (1979). Martingales and Arbitrage in Multi-Period Securities Markets. Journal of Economic Theory, 20, 381-408.

Harrison, M. J., \& Pliska, S. R. (1981). Martingales and Stochastic Integrals in the Theory of Continuous Trading. Stochastic Processes and their Applications, $11,215-260$.

Harrison, M. J., \& Pliska, S. R. (1983). A Stochastic Calculus Model of Continuous Trading: Complete Markets.
Stochastic Processes and Their Applications, 15, 313-316.

Kogan, L., Makarov, I., \& Uppal, R. (2007). The Equity Risk Premium and the Riskfree Rate in an Economy with Borrowing Constraints. Mathematics and Financial Economics, 1(1), 1-19.

Merton, R. E. (1972). An Analytic Derivation of the Efficient Portfolio Frontier. The Journal of Financial and Quantitative Analysis, 7(4), 1851-1872.

Pereda, J. (2007). Estimación de la Frontera Eficiente para las AFP en el Perú y el Impacto de los Límites de Inversión: 1995-2004. Serie Documentos de Trabajo $\mathrm{N}^{\circ}$ 2007-009. Obtenido de <http://econpapers. repec.org/paper/rbpwpaper/2007-009.htm>.

Rivas-Llosa, R., \& Camargo, G. (2002). Límites de inversión para las AFP: ¿son financieramente eficientes? Punto de Equilibrio, Año 11(79), 40-41.

Ross, S. A. (1977). The Capital Asset Pricing Model (CAPM), Short-Sale Restrictions and Related Issues. The Journal of Finance, 32(1), 177-183.

Sharpe, W. F. (1970). Portfolio Theory and Capital Markets. New York: McGraw-Hill Book Co.

Shanken, J. (1996). Statistical Methods in Test of Portfolio Efficiency: A Synthesis. In G. S. Maddala \& C. R. Rao (eds.) Handbook of Statistics, Vol. 14 (pp. 693701). Amsterdam: Elsevier Science B.V.

Stoll, H. R., \& Whaley, R. E. (1993). Futures and Options: Theory and Applications. Cincinnati, $\mathrm{OH}$ : South-Western Education Publishing.

Tobin, J. (1958). Liquidity Preference as Behaviour Towards Risk. Review of Economic Studies, 67, 65-86. 


\section{ANEXO A}

Matriz de correlaciones

\begin{tabular}{lcccccccc}
\hline & B. Gob. & CD-BCR & Bonos & Acciones & Dep. & Dep. ME & Accs. Ext. & Dep. Ext. \\
Bonos del Gobierno & 1,000 & 0,102 & 0,445 & 0,135 & MN & 0,084 & $-0,013$ & $-0,086$ \\
CD_BCR & & 1,000 & 0,407 & $-0,600$ & 0,194 & 0,759 & 1,456 & 0,688 \\
Bonos & & & 1,000 & $-0,196$ & 0,830 & 0,643 & 0,203 & 0,490 \\
Acciones & & & & 1,000 & 0,191 & $-0,393$ & 0,150 & $-0,521$ \\
Depósitos MN & & & & $-0,489$ & 0,532 & 0,324 & 0,441 \\
Depósitos ME & & & & 1,000 & 1,000 & 0,670 & 0,895 \\
Acciones Ext. & & & & & & & & \\
Depósitos Ext. & & & & & & & & \\
\hline
\end{tabular}

\section{ANEXO B}

Composición de carteras de mínima varianza

(Valores porcentuales)

\begin{tabular}{lccc}
\hline & Límites legales & Límites $+/-5 \%$ & Límites $+/-10 \%$ \\
\hline Bonos del Gob. &.-- &.-- &.-- \\
CD-BCRP & 30,000 & 35,000 & 40,000 \\
Bonos & 46,077 & 44,191 & 42,183 \\
Acciones Domésticas & 6,749 & 6,845 & 6,952 \\
Depósitos en MN & 17,015 & 13,964 & 10,865 \\
Depósitos en ME &.-- &.-- &..- \\
Acciones del Exterior &.-- &.-- &.-- \\
Depósitos del Exterior & 0,159 &.-- &.-- \\
Rendimiento & 13,140 & 13,091 & 13,040 \\
Riesgo & 3,128 & 3,118 & 3,113 \\
\hline
\end{tabular}

ANEXO C

Variación de Límites

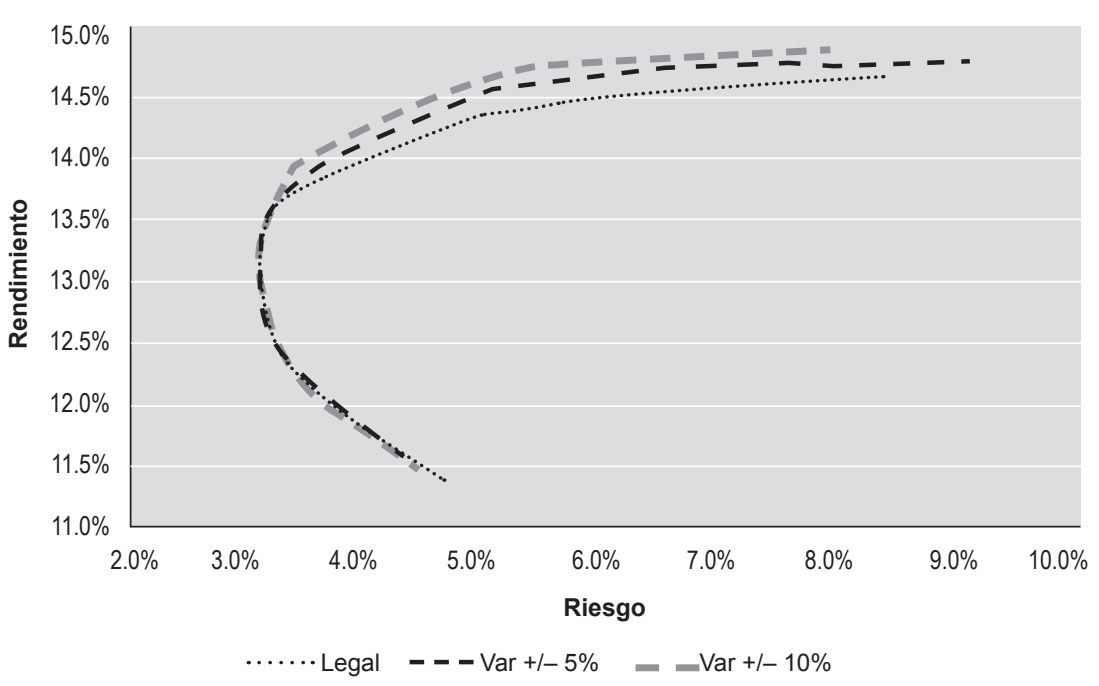

J. econ. finance adm. sci., 15(29), 2010 